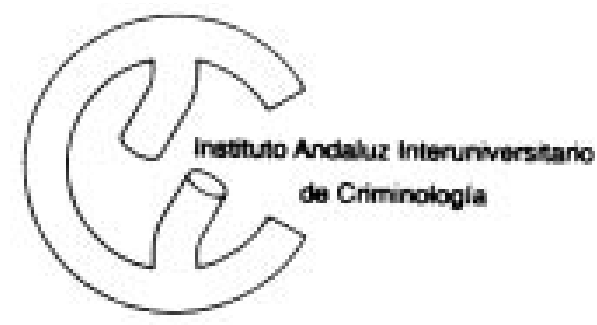

Director: Per Stangeland

Coordinadora: Ma José Garrido de los Santos Publicado por la Sección de Málaga del IAIC Facultad de Derecho, Universidad de Málaga Campus de Teatinos, 29071 MALAGA Tel:(95) 2132325 - Fax:(95) 2132242 Depósitolegal:MA857/1996ISSN:1137-2427

Internet: Http://emn.derecho.uma.es/crimi

El creciente interés por la protección del medio ambiente en España se traduce, poco a poco, en el establecimiento de un control formal más eficaz. En este ámbito, la actividad del servicio de Protección de la Naturaleza de la Guardia Civil, SEPRONA, es de gran importancia. De este trabajo del director del I.A.I.C. en Córdoba, Horacio Roldán, se deduce que la mayoría de las denuncias por infracciones administrativas se refiere a la caza furtiva, mientras que los incendios forestales representan el grueso de los atestados por infracciones penales. El esclarecimiento de estos delitos y la detención del autor es poco frecuente.

\title{
Infracciones penales contra el medio ambiente: EL SEPRONA
}

Autor:

Horacio Roldán Barbero
El art. 12 de la Ley de Fuerzas y Cuerpos de Seguridad de 1986 atribuyó a la Guardia Civil la función de «velar por el cumplimiento de las disposiciones que tiendan a la conservación de la naturaleza y medio ambiente, de los recursos hidráulicos, así como de la riqueza cinegética, piscícola, forestal y de cualquier otra índole relacionada con la naturaleza».

Para efectuar de manera específica dicha función se creó, en 1988, el SEPRONA. En sus dos primeros años, el citado servicio no llevó a cabo una labor concreta de investigación por ser época de organización. A partir de 1990 comenzó su labor de control en lo referente a las infracciones medio ambientales.

Ya en ese momento se contaba con un corpus normativo, amplio y disperso, en el que se tipificaban muchas infracciones contra el medio ecológico. Entonces como ahora, la mayor parte de esas infracciones tiene un carácter administrativo. No obstante, los preceptos penales han ido creciendo en número, sobre todo desde la entrada en vigor, en mayo de 1996, del nuevo Código Penal, aunque

Gráfica 1. Evolución de las denuncias incoadas por el SEPRONA y otras unidades del cuerpo de la Guardia Civil en materia medioambiental

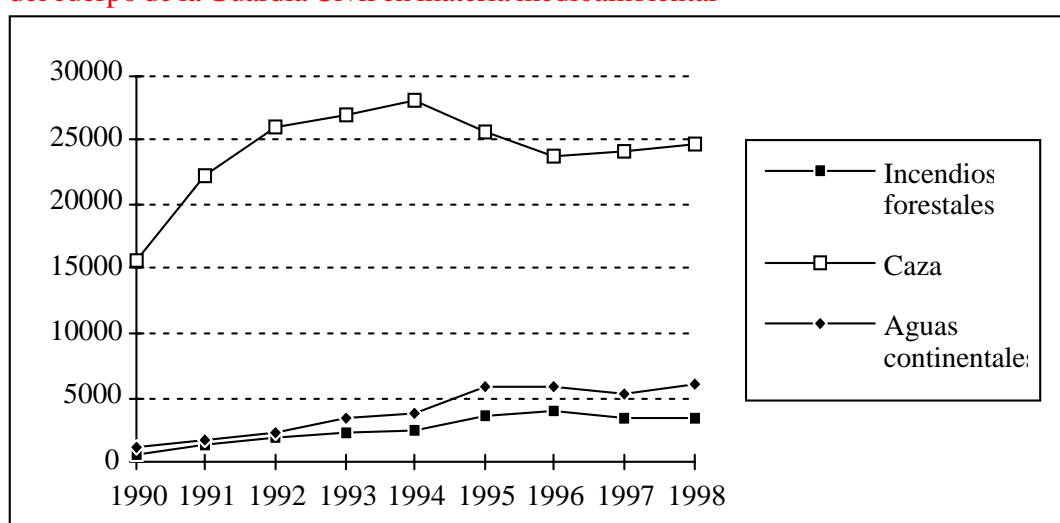

este crecimiento legal no ha redundado en un aumento práctico de las actuaciones penales.

Sea como quiera, no puede ponerse en duda la conveniencia de la creación de una «policía» encargada específicamente de asuntos ecológicos.

La Guardia Civil no es, en cualquier caso, la única instancia policial de control formal en materia medio ambiental. Algunas Policías locales cuentan también con las llamadas «patrullas verdes»y, en el ámbito autonómico, hay diversas Policías que ejercen funciones específicas en este campo; tal es el caso de la Policía autónoma andaluza, la cual, a partir de 1994, cuen- ta con una unidad cuyo cometido principal se manifiesta dentro de las «Campañas de INFOCA» relativas a la lucha contra los incendios forestales.

En el Ministerio fiscal también se viene observando desde hace bastantes años una preocupación por dar la respuesta esperada a la delincuencia ecológica. Han sido frecuentes las recomendaciones contenidas en diversas Memorias fiscales en favor de la creación de Secciones especializadas en asuntos medio ambientales, las cuales habrán de asumir un papel decisivo en las llamadas diligencias de investigación penal.

Son, pues, muy diversas las res-

\section{Boletín Criminológico $N^{o} 43$ Septiembre-Octubre 1999 Página 1}


puestas formales en lo relativo a las infracciones contra el medio natural, aunque sin duda alguna es la Guardia Civil, a través del SEPRONA, la instancia que deja notar más su presencia. De ahí que le hayamos dedicado a ella este breve trabajo, en el que pretendemos mostrar cuáles son los resultados más visibles de su actividad. Las conclusiones obtenidas han derivado de dos fuentes de información:

a) La propia estadística interna.

b) La entrevista personal con algunos miembros del servicio.

CARACTERISTICAS GENERALES DE LA ESTADISTICA DEL SEPRONA

El SEPRONA elabora, desde 1990, una Estadística sobre intervenciones realizadas tanto por la unidad de dicho servicio como por otras unidades del Cuerpo que pueden intervenir en su caso en materia medioambiental. De la misma manera, entre los asuntos objeto de actuación por el SEPRONA, también puede haber algunos otros ajenos a la materia de su competencia formal. Por tanto, el SEPRONA es una unidad especializada, pero no exclusiva, en la prevención/represión de las ilicitudes de carácter ecológico. Su ámbito territorial abarca todo el marco geográfico español, a excepción del País Vasco en donde la Ertzaintza ejerce estas tareas en su condición de policía integral.

En los resúmenes estadísticos se clasifican las intervenciones en denuncias, atestados y actas. Las primeras se instruyen por infracciones administrativas; los segundos por infracciones penales (delitos y faltas); mientras que las terceras tienen un carácter mixto, no muy claro aparentemente, pero que, según explicaciones de responsables de la unidad, se refieren a casos de contrabando de especies o productos cuya comercialización está prohibida, de los que sólo un $10 \%$ aproximadamente tienen significación penal (art.
2, 1 f) de la Ley de Contrabando de 1995).

Las conductas ilícitas en materia ecológica se concretan predominantemente en infracciones administrativas. Los datos son bien explícitos, según se puede apreciar en el siguiente cuadro, del que se excluyen las actuaciones por asuntos distintos a la especialidad:

$\begin{array}{llc} & \text { Denuncias } & \text { Atestados } \\ \mathbf{1 9 9 1} & 46.551 & 3.094 \\ \mathbf{1 9 9 2} & 58.801 & 2.704 \\ \mathbf{1 9 9 3} & 71.418 & 2.653 \\ \mathbf{1 9 9 4} & 84.285 & 4.433 \\ \mathbf{1 9 9 5} & 85.539 & 4.785 \\ \mathbf{1 9 9 6} & 102.347 & 2.333 \\ \mathbf{1 9 9 7} & 91.633 & 2.130 \\ \mathbf{1 9 9 8} & 101.085 & 2.506\end{array}$

Las infracciones de carácter penal representan un porcentaje pequeño en el total de intervenciones, por denuncias y atestados, realizadas por el SEPRONA. Sus cifras relativas oscilan entre el $2,23 \%$, en 1996 , y el $6,23 \%$, en 1991.

En la asignación al ámbito de las infracciones administrativas o al de las penales influye una concepción previa de lo que la Guardia Civil considera objeto de uno y otro sector jurídico. El cuerpo opera con unas instrucciones internas al respecto, acompañadas de unos comentarios a los preceptos del Código Penal objeto de su actividad. Sus miembros tienen muy claro que su labor debe estar informada por el principio de intervención mínima, de tal suerte que al orden penal deben reservarse los atentados más graves contra los distintos elementos del espacio ecológico. Sin embargo, también conocen el principio procesal de la preferencia del orden penal respecto al administrativo, repetido hasta la saciedad en toda la legislación medio ambiental, cuando el hecho presente los caracteres de delito. Aun así, es más que posible que en determinados asuntos, sobre todo en la mayoría de los que se aglutinan en el art. 325 del C.P. -denominado un tanto vagamente delito ecológico-, su preconcepción no coincida con la de los Jue- ces.

\section{CAMPOS PRINCIPALES DE ACTUACION}

Desde sus primeros años de actividad, el SEPRONA incluye en sus resúmenes estadísticos una serie de conceptos teóricos relacionados con las conductas ilícitas en materia ecológica, en los cuales quedan anotados las denuncias, atestados y actas practicados. Estos conceptos no han permanecido inalterados a lo largo de los años, sino que a los iniciales se han sumado otros, o bien algunos de aquéllos se han eliminado de la relación o se han conjuntado con otros.

En los resúmenes estadísticos de 1998 figuran 28 apartados: obras y edificaciones, leyes sanitarias, extracción de minerales, espacios protegidos, turismo y deportes, bosques y montes, incendios forestales, patrimonio histórico, contaminación atmosférica, aguas continentales, aguas marítimas, costas, caza, pesca continental, pesca marítima, residuos sólidos urbanos, residuos tóxicos y peligrosos, convenio cites, otros convenios, otros A (materia medio ambiental no comprendida en los epígrafes anteriores) y otros B (asunto ajeno a la especialidad). Toda actuación se refleja sólo en un apartado; el agente ha de decidirse por uno u otro epígrafe.

Esta clasificación conceptual responde más a consideraciones jurídico-administrativas que penales. Introduce distintos criterios en la pormenorización de los epígrafes: las claves o elementos que componen el medio ambiente (contaminación atmosférica, aguas continentales, aguas marítimas); el espacio físico o la ocasión donde se produce la infracción (obras y edificaciones, costas, caza, turismo y deportes); el texto normativo internacional donde se regula el concepto (convenio cites, en relación al comercio de especies).

La distribución de las actuaciones pudiera ser a veces aleatoria. Por ejemplo, una construcción realizada en una zona prohibida por

\section{Boletín Criminológico $N^{o} 43 \quad$ Septiembre-Octubre 1999 Página 2}


Grafica 2. Evolución de los atestados incoados por el SEPRONA y otras unidades del cuerpo de la Guardia Civil en materia medioambiental

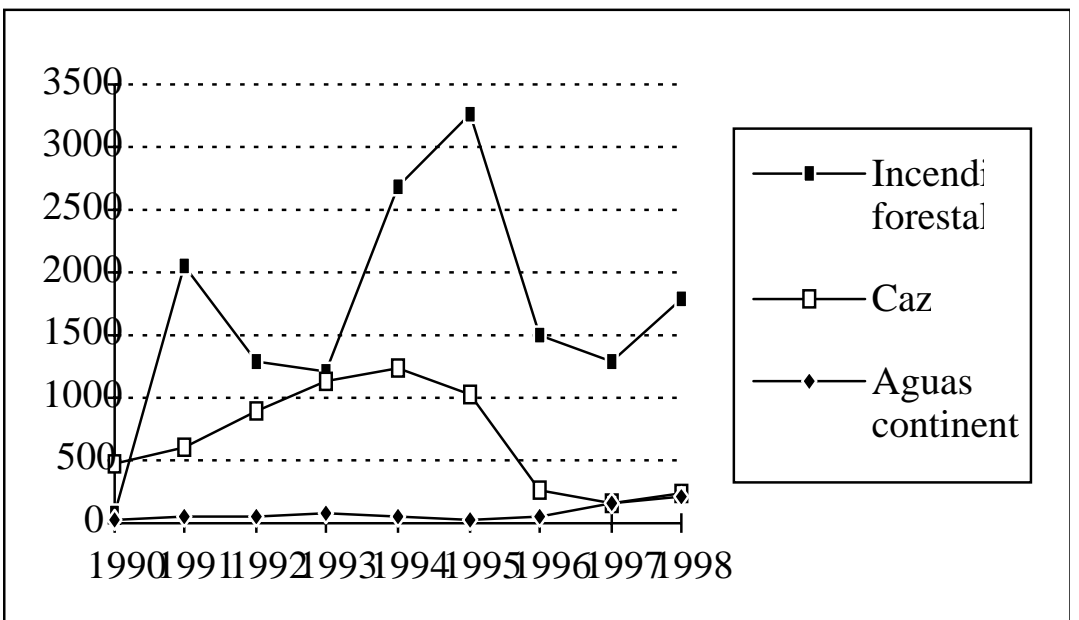

su proximidad al litoral puede ser incluida tanto en el epígrafe «obras y edificaciones» como en el de «costas». Una extracción o excavación en el monte puede ser igualmente clasificada en «extracción de minerales» o en «bosques o montes».

Se aprecia que existen conceptos que, en su traducción jurídicopenal, no responden propiamente a los delitos contra el medio ambiente. Éste es el caso del patrimonio histórico. Se alega, no obstante, que de este campo temático sólo se ocupa la unidad si se trata de un atentado arqueológico. De forma más acentuada, ocurre esto también con el turismo y los deportes, donde no se ve en principio su relación con el medio ambiente. En cambio, no se han reflejado todavía como campos temáticos la contaminación atmosférica por ruidos y vibraciones, los atentados contra la flora, ni tampoco el maltrato cruel a animales.

La ordenación de los apartados debiera pasar por una concreción de las claves o elementos medio ambientales: el aire, en el doble aspecto de su contaminación por emisiones o por ruidos; el agua, tanto la continental como la marítima; el suelo y el subsuelo, incluyendo la racional ordenación de los mismos; el medio forestal; la fauna, tanto terrestre como marítima; la flora. Esas claves no tienen por qué coincidir con la sistemática de las leyes administrativas o del C.P.
Resulta incontestable, por ejemplo, que los incendios forestales arramblan con elementos nucleares del medio ambiente, por más que el C.P. no parezca verlo así, al haberlos regulado entre los delitos contra la seguridad colectiva.

\section{Incendios forestales}

Desde el punto de vista práctico, es el delito ecológico por antonomasia. Cada año el SEPRONA incoa más de mil atestados por este delito y, en algún año, como sucedió en el seco de 1995, la cifra superó las tres mil actuaciones penales (véase gráfica 2).

Las causas de los incendios forestales se han expuesto repetidas veces y son variadas: creación de pastizales, intereses cinegéticos, urbanísticos, gamberrismo, rencillas, entre los incendios dolosos; y fumadores descuidados, quema de rastrojos y basureros, hogueras, entre los incendios imprudentes.

Aparte de existir razones criminológicas muy diversas, lo que ya propicia una probabilidad estadística muy alta de comisión de este delito, la decantación por la infracción penal aparece liberada de obstáculos jurídico-formales, en la medida en que el tipo doloso, en su modalidad atenuada, comienza con el mero hecho de prender fuego a montes o masas forestales sin que llegue a propagarse (art. 354 C.P.). Asimismo, al incriminarse la imprudencia grave (art. 358 C.P.), también habrá de hacerse un atestado en los muy numerosos casos en los que los agentes no aprecian el carácter fortuito o accidental del incendio.

\section{Caza}

Es el segundo campo relevante en la delincuencia ecológica e incontestablemente el primero entre las infracciones administrativas (véase gráfica 1). La cifra de atestados por motivos cinegéticos ha ido creciendo ininterrumpidamente desde 1990 a 1994. La inflexión se produce débilmente en 1995 , continuando en un acentuado sentido descendente en los años siguientes. Así, en 1997, sólo se realizaron 176 atestados por motivos de caza, cuando en 1994 se había llegado a 1.248 (véase gráfica 2).

Puede parecer contradictorio que la entrada en vigor del Código Penal haya procurado este considerable descenso, si reparamos que en dicho código existe todo un capítulo dedicado a los delitos contra la fauna. Pese a la apariencia, el grueso de las infracciones en materia de caza ha quedado relegado al ámbito administrativo por virtud de la Disposición Derogatoria Primera e) del nuevo C.P. A la legislación penal sólo ha quedado confiada la caza de las especies en peligro de extinción, amenazadas o protegidas en algún grado bajo otras consideraciones. El abatimiento de los llamados animales cazables en la época de veda (la infracción más frecuente) es, justamente, la que se reputa ahora ilícito administrativo. No parece, por lo demás, que el resto de conductas penales contra la fauna (impedir o dificultar la reproducción o migración, o comerciar o traficar con las especies amenazadas o en peligro de extinción) pueda estar, de momento, en condiciones de compensar la pérdida de influencia del Derecho penal en este terreno.

\section{Boletín Criminológico $N^{o} 43$ Septiembre-Octubre 1999 Página 3}




\section{Aguas continentales}

En este tercer ámbito de interés, las actuaciones penales practicadas por el SEPRONA ya casi igualaron, en 1997 y en 1998, a las realizadas por motivos de caza. En concreto, fueron 167 y 224, respectivamente, los atestados en materia de aguas continentales en esos dos años (véase gráfica 2).

Junto a la conducta prototípica de los vertidos en aguas superficiales, el nuevo C.P. refuerza la protección hidrológica incriminando la conducta de captación de aguas subterráneas; mas no parece que por ahora, y hasta la próxima y malhadada sequía, esta conducta vaya a poder perjudicar gravemente el equilibrio de los sistemas naturales, como exige el C.P. (art. 325 C.P.).

El número creciente de atestados en materia de aguas continentales deriva también de la mejora en el control directo de la Guardia Civil. Aparte de sus análisis propios, el SEPRONA puede recurrir a las Confederaciones Hidrográficas a efectos de fundamentar el atestado. Al poderse objetivar éste en virtud de unos parámetros previamente establecidos, el campo abonado a la actuación penal no aparece de entrada tan incierto como el existente en otras facetas.

Otros muchos son los capítulos de interés en el ámbito de la delincuencia medio ambiental. Una reforzada línea de investigación debe abrirse en el futuro en lo concerniente a los vertederos ilegales, susceptibles ahora de ser tipificados tanto por el art. 325 como por el 328 C.P., juego de preceptos oscuro, urgido de clarificación. En lo que respecta a la contaminación atmosférica, el control social formal es manifiestamente mejorable, pese a ciertos intereses económicos que puede haber en contra. Se barrunta también como poco eficiente la actuación policial en materia de pesca, tanto continental como marítima, aunque se halle en estudio una mejor respuesta en la captura de inmaduros. La

\section{DETENIDOS}

Una información que está ausente en la Estadística del SEPRONA es la del número de esclarecimientos de las infracciones penales. Según las Memorias fiscales, se decretan muchos sobreseimientos judiciales por falta de autor conocido, lo cual es particularmente expresivo en el principal delito ecológico, los incendios forestales. De ahí se deriva que el número de esclarecimientos debe ser bastante bajo.

Si nos atenemos al dato de los detenidos por delitos contra el medio ambiente, que sí figura en la Estadística, queda reforzada la imagen de la falta de éxito policial en la averiguación de la autoría de los hechos delictivos. Por miembros del SEPRONA se sostiene, sin embargo, que existen actuaciones penales que son esclarecidas pese a que respecto a ellas, por aplicarse el art. 493 LECrim, no se practiquen detenciones. La cifra de esclarecimientos sería, en consecuencia, mayor que la de las detenciones. En el siguiente cuadro, del que se han excluido las actuaciones por motivos ajenos a la especialidad, se refleja la evolución de los detenidos por causas medio ambientales:

$\begin{array}{ccc}\text { Detenciones } & \begin{array}{c}\text { \% de Atestados } \\ \text { en que hay detenciones }\end{array} \\ \mathbf{1 9 9 1} & 345 & 11,15 \\ \mathbf{1 9 9 2} & 467 & 17,27 \\ \mathbf{1 9 9 3} & 561 & 21,15 \\ \mathbf{1 9 9 4} & 896 & 20,21 \\ \mathbf{1 9 9 5} & 623 & 13,02 \\ \mathbf{1 9 9 6} & 315 & 13,50 \\ \mathbf{1 9 9 7} & 345 & 16,20 \\ \mathbf{1 9 9 8} & 330 & 13,16\end{array}$

Se observa cómo, tras la entrada en vigor del C.P. y la consiguiente disminución de los atestados por infracciones penales en materia de caza, el número de detenidos desciende de manera sensible; pues eran los delitos de caza los que daban ocasión al número más alto de detenciones.

El bajo porcentaje de detenciones practicadas por la Guardia Civil contrasta con la mayor propensión de la Policía autónoma andaluza a detener a los presuntos autores de los incendios forestales. El número global de atestados realizados por la Policía autónoma no es comparable al del SEPRONA, pero en términos relativos el porcentaje de detenidos por diligencias tramitadas es muy elevado:

199616 de $58(27,59 \%)$

199737 de $107(34,58 \%)$

199851 de $89(57,30 \%)$

Estos datos invitan a pensar que los criterios de actuación respecto a la detención son diversos en uno y otro cuerpo policial. Acaso también evidencian que la Policía regional se muestra más eficaz, dentro de su muy reducido ámbito de actuación, en los esclarecimientos de los delitos objeto de su competencia.

tipificación de los delitos contra la ordenación del territorio debe paliar también, mediante reacciones contundentes, el deterioro y afeamiento crecientes de nuestra geografía.

De momento, el peso del control formal se canaliza en todos estos ámbitos a través de la de- nuncia administrativa, sin que en ningún caso el número de infracciones penales en relación a cada uno se aproxime a la cifra de 100 atestados anuales.

Nota: Quiero manifestar mi agradecimiento a D. José Antonio Sánchez Arroyo, y D. Antonio Montaño, del SEPRONÂ, así como a D. Atilano Sánchez Vaquero, de la Policía autónoma andaluza.

\section{Boletín Criminológico $N^{o} 43$ Septiembre-Octubre 1999 Página}

